\title{
Phonomyographic measurements of neuromuscu- lar blockade are similar to mechanomyography for hand muscles
}

\author{
[Les mesures phonomyographiques du blocage neuromusculaire sont similaires à \\ celles de la mécanomyographie pour les muscles de la main]
}

Thomas M. Hemmerling MD DEAA, Guillaume Michaud, Guillaume Trager MSc, Stéphane Deschamps MSc

\begin{abstract}
Purpose: Phonomyography consists of recording low frequency sounds created during muscle contraction. In this study, phonomyography of three regions of the hand was compared to mechanomyography of the adductor pollicis.
\end{abstract}

Methods: In 12 patients, phonomyography was recorded via small condenser microphones taped over the thenar mass, the hypothenar eminence, and the dorsal groove between the first and second metacarpal bones to record the acoustic signals of adductor pollicis and the hypothenar and first dorsal interosseus muscles, respectively. Mechanomyography of the adductor pollicis was recorded simultaneously using a force transducer. After induction of anesthesia, the ulnar nerve was stimulated supramaximally using train-of-four (TOF) stimulation every $12 \mathrm{sec}$. Onset, maximum effect, and offset of neuromuscular block after rocuronium 0.6 $\mathrm{mg} \cdot \mathrm{kg}^{-1}$ were measured using phonomyography and compared to mechanomyography using ANOVA and the Bland-Altman test.

Results: Phonomyographic measurements of onset and maximum effect of neuromuscular blockade were not significantly different from mechanomyographic measurements. Phonomyographic measurements of offset (T25\%, T75 \%, TOF 0.8) of neuromuscular block at the thenar muscles and first dorsal interosseus muscles were not significantly different from mechanomyographic measurements at adductor pollicis; however, T50\%, T75\% and T90\% phonomyographic measurements at the hypothenar muscle were significantly shorter than at any other muscle site.

Conclusion: There was good agreement between mechanomyographic measurements at the adductor pollicis muscle and phonomyographic measurements at the thenar and the first dorsal interosseus muscles. Phonomyography of those two muscles could be used interchangeably with mechanomyography of adductor pollicis for clinical purposes.
Objectif : La phonomyographie consiste à enregistrer les sons de
basse fréquence créés pendant la contraction musculaire. Dans la
présente étude, la phonomyographie de trois régions de la main a été
comparée à la mécanomyographie de l'adducteur du pouce.

Méthode : La phonomyographie a été enregistrée chez 12 patients avec des petits microphones à condensateurs fixés sur la paume, l'éminence hypothénar et le sillon dorsal entre le premier et le second os métacarpien pour enregistrer les signaux acoustiques de l'adducteur du pouce, du muscle hypothénar et du premier muscle dorsal interosseux, respectivement. La mécanomyographie de l'adducteur du pouce a été enregistrée simultanément avec un transducteur de force. Après l'induction de l'anesthésie, le nerf cubital a été soumis à une stimulation supramaximale utilisant un train-de-quatre (TDQ) toutes les $12 \mathrm{sec}$. Le délai d'installation du bloc, son effet maximal et son extinction après l'administration de $0,6 \mathrm{mg} \cdot \mathrm{kg}^{-1}$ de rocuronium, ont été mesurés par phonomyographie et comparés à la mécanomyographie par l'analyse de la variance et le test Bland-Altman.

Résultats : Les mesures phonomyographiques du délai d'installation et de l'effet maximal n'étaient pas significativement différentes des mesures mécanomyographiques. Avec la phonomyographie, les mesures de l'extinction du bloc (T25\%, T75 \%, TDQ 0,8) neuromusculaire au muscle thénar et au premier muscle interosseux dorsal n'ont pas été significativement différentes des mesures mécanomyographiques à l'adducteur du pouce ; cependant, les mesures phonomyographiques des T50 \%, T75 \% et T90 \% au muscle hypothénar ont été significativement plus courtes qu'à tout autre site musculaire.

Conclusion : II y a une bonne concordance entre les mesures mécanomyographiques de l'adducteur du pouce et les mesures phonomyographiques des muscles thénar et premier interosseux dorsal. La phonomyographie de ces deux muscles peut être utilisée de façon interchangeable avec la mécanomyographie de l'adducteur du pouce en clinique.

From the Neuromuscular Research Group (NRG), Department of Anesthesiology, Centre Hospitalier de l'Université de Montréal (CHUM) Hôtel-Dieu, Université de Montréal, Montréal, Québec, Canada.

Address correspondence to: Dr. T.M. Hemmerling, Department of Anesthesiology, Université de Montréal, Hôtel-Dieu, 3840, rue St-

Urbain, Montréal, Québec H2W 1T8, Canada. Phone: 514-890-8000, ext. 14570; Fax: 514-412-7222;

E-mail: thomashemmerling@hotmail.com

This work was performed using departmental internal funds. In addition, Dr. Hemmerling is recipient of the 2003 Career Scientist Award of the Canadian Anesthesiologists' Society which provides salary support.

Accepted for publication December 15, 2003.

Revision accepted February 13, 2004. 
$\mathrm{P}$ HONOMYOGRAPHY (PMG) has been presented as a novel method to record neuromuscular blockade (NMB) with high sensitivity, easy applicability and use at several muscles, including the adductor laryngeal muscles ${ }^{1}$ and the corrugator supercilli. ${ }^{2}$ The technique is based on the generation of low-frequency sounds by the lateral movement of muscle fibrils during muscle contraction. Muscles of the hand have long been used in research and clinical practice as targets of NMB and reference sites for neuromuscular monitoring. In addition, monitoring of the hand muscles is easy and essential for determination of complete muscular recovery after NMB during surgery. Several intrinsic hand muscles can be used to monitor NMB of the patient, mainly the adductor pollicis muscle, but also the hypothenar and first dorsal interosseus muscles. ${ }^{3,4}$ Because of different innervation, blood perfusion and tissue composition, these muscles are prone to different responses to non-depolizaring agents. The goal of this study was to compare measurements of NMB after rocuronium $0.6 \mathrm{mg} \cdot \mathrm{kg}^{-1}$ at all three muscle sites of the hand (first dorsal interosseus, the hypothenar muscles, and the thenar muscle group) using PMG with measurements of NMB at the adductor pollicis muscle using mechanomyography (MMG).

\section{Methods}

After approval of the local Ethics Committee and obtaining informed consent, 12 patients undergoing general surgery were included in the study. Patients who had co-existing neuromuscular disease or were taking medication known to interact with neuromuscular transmission were excluded.

After arrival in the operating room, routine monitors (non-invasive blood pressure cuff, pulse oximeter, five-lead electrocardiogram) were applied. Anesthesia was induced with remifentanil 0.25 to 0.5 $\mu \mathrm{g} \cdot \mathrm{kg}^{-1} \cdot \mathrm{min}^{-1}$; two minutes later, propofol 2 to 3 $\mathrm{mg} \cdot \mathrm{kg}^{-1}$ were injected. After loss of consciousness and ventilation via face mask for two minutes with $100 \%$ oxygen, a laryngeal mask airway (size 4 for women, size 5 for men; LMA Company, Henley on Thames, UK) was inserted and controlled ventilation commenced with minute ventilation set to maintain a $\mathrm{PETCO}_{2}$ of 25 to $35 \mathrm{mmHg}$. Anesthesia was maintained with 1 to $1.5 \mathrm{MAC}$ of sevoflurane in a gas mixture of $30 \%$ oxygen in air to maintain a bispectral index of 50 (BIS, A-2000 monitoring system, Aspect Medical Company, Newton, IA, USA). Analgesia was provided by remifentanil 0.05 to $0.25 \mu \mathrm{g} \cdot \mathrm{kg}^{-1} \cdot \mathrm{min}^{-1}$ throughout surgery. In all patients, the force of contraction of the adductor pollicis was measured using a

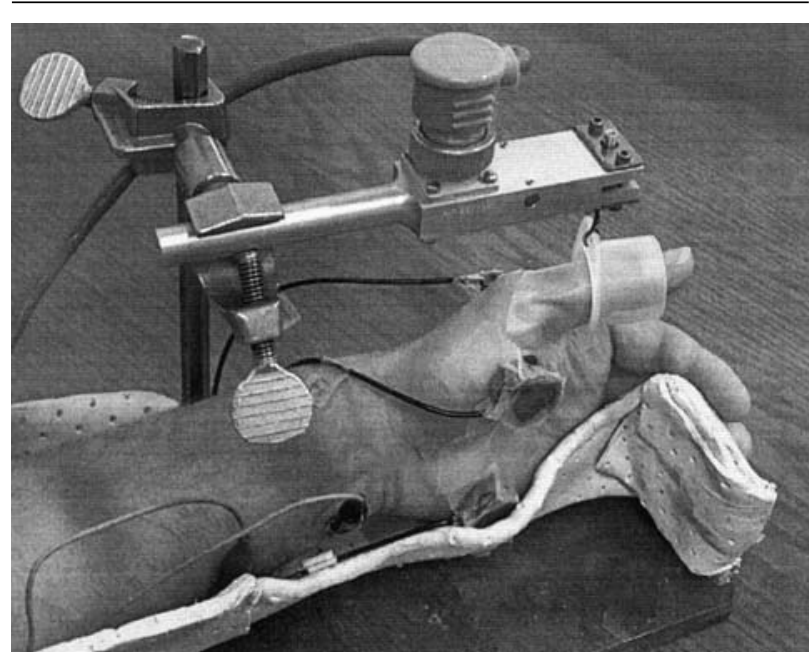

FIGURE 1 Illustration of location of the microphones over the first dorsal interosseus, thenar, and hypothenar muscles. The force transducer is also fixed to the thumb to monitor the adductor pollicis muscle. A specially molded cast was used to fix the hand to the operating table. Phonomyographic and mechanomyographic signals were acquired simultaneously.

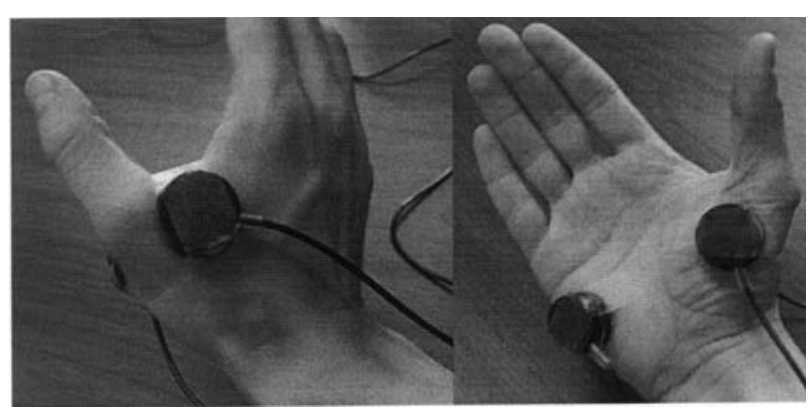

FIGURE 2 Positioning of the three microphones to monitor neuromuscular blockade of the first dorsal interosseus muscle (left), the adductor pollicis (right, thenar eminence), and the three hypothenar muscles (right, hypothenar eminence).

force transducer. A specially molded cast was used to stabilize the arm in position (Figure 1). A small condenser microphone $(1.6 \mathrm{~cm}$ diameter, Model 1010, Grass Instruments, Astro-Med, Inc., West Warwick, RI, USA; frequency response: $2.5 \mathrm{~Hz}$ to $5 \mathrm{kHz}$, signal output: $20-40 \mathrm{mV}$ into $\mathrm{l} \mathrm{M} \Omega$ ) was attached to the middle of the thenar mass using tape to record the acoustic signals produced by the contraction of the 
TABLE

\begin{tabular}{|c|c|c|c|c|}
\hline & $\begin{array}{l}\text { First dorsal } \\
\text { interosseus (PMG) }\end{array}$ & $\begin{array}{l}\text { Thenar } \\
\text { (PMG) }\end{array}$ & $\begin{array}{l}\text { Hypothenar } \\
(P M G)\end{array}$ & $\begin{array}{l}\text { Adductor pollicis } \\
(M M G)\end{array}$ \\
\hline Maximum effect (\%) & $95.1 \pm 4.4$ & $92.9 \pm 3.7$ & $91.9 \pm 3.9$ & $91.4 \pm 4.1$ \\
\hline Onset $(\min )$ & $4.3 \pm 2.0$ & $4.2 \pm 2.0$ & $4.0 \pm 1.8$ & $3.7 \pm 1.9$ \\
\hline $\mathrm{T} 25 \%(\mathrm{~min})$ & $33.2 \pm 10.4$ & $32.4 \pm 9.3$ & $28.1 \pm 8.4$ & $30.4 \pm 7.6$ \\
\hline $\mathrm{T} 50 \%(\mathrm{~min})$ & $40.7 \pm 12.9$ & $40.7 \pm 11.8$ & $\begin{array}{l}35.0 \pm 10.1 \\
(P=0.007)\end{array}$ & $38.5 \pm 10.1$ \\
\hline $\mathrm{T} 75 \%(\mathrm{~min})$ & $46.8 \pm 14.6$ & $47.3 \pm 13.8$ & $\begin{array}{l}40.4 \pm 12.4 \text { * } \\
(P=0.015)\end{array}$ & $45.0 \pm 11.9$ \\
\hline T90 \% (min) & $53.3 \pm 17.0$ & $54.3 \pm 16.7$ & $\begin{array}{l}44.8 \pm 14.9 \text { * } \\
(P=0.001)\end{array}$ & $50.8 \pm 13.0$ \\
\hline TOF 0.8 (min) & $60.2 \pm 23.2$ & $59.6 \pm 22.0$ & $60.5 \pm 19.3$ & $61.1 \pm 23.4$ \\
\hline $\mathrm{RI}(\min )$ & $11.5 \pm 4.7$ & $12.6 \pm 4.6$ & $11.5 \pm 4.1$ & $11.3 \pm 4.1$ \\
\hline
\end{tabular}

$\mathrm{PMG}=$ phonomyography $\mathrm{MMG}=$ mechanomyography. $\mathrm{RI}=$ recovery index. Data are expressed as mean \pm standard deviation. Maximum effect $=$ maximum decrease of control twitch height. Onset time $=$ time to reach maximum effect. T25\%, T75\%, T90\% $=$ time to reach $25 \%, 75 \%, 90 \%$ of control twitch height. TOF $0.8=$ time to reach a train-of-four ratio of 0.8 . Time to $75 \%$ of control twitch height minus time to $25 \%$ of control twitch height (T75\% - T25\%). *Significant difference when compared to MMG data.

adductor pollicis muscle (Figure 2). Another small condenser microphone was glued over the first dorsal interosseus muscle about $3 \mathrm{~cm}$ proximal to the second metacarpophalangeal joint to record acoustic signals evoked by contraction of the first dorsal interosseus muscle. A third microphone was attached to the eminence of the hypothenar muscles to record acoustic signals evoked by its contraction. The microphone signals were amplified and band pass filtered between 0.5 $\mathrm{Hz}$ and $1000 \mathrm{~Hz}$ using an AC/DC amplifier. The phonomyographic and mechanomyographic signals were continuously sampled at $100 \mathrm{~Hz}$ using the Polyview ${ }^{\circledR}$ software package (Astra Medical Company), digitized and stored on a portable microcomputer. The twitch amplitude from PMG and MMG signals was measured peak-to-peak (Figure 3).

In all patients, the ulnar nerve was stimulated at the forearm with train-of-four (TOF) supramaximal stimulation each $12 \mathrm{sec}$ via surface electrodes using a constant current stimulator (Innervator ${ }^{\circledR}$, Fisher and Paykel Healthcare, Auckland, New Zealand). Current intensity was between 10 and $70 \mathrm{~mA}$. Supramaximal stimulation was determined using single-twitch stimulation at $0.1 \mathrm{~Hz}$. When all four signals were stable and free of artefacts, rocuronium $0.6 \mathrm{mg} \cdot \mathrm{kg}^{-1}$ were injected within five seconds into a fast flowing solution of Ringer's lactate. Onset, maximum effect, and offset of NMB were determined. Recordings of signals were continued until TOF were greater than 0.9 in all patients.

The first twitch response was used to analyze onset time (time to reach maximum decrease of twitch response), time to reach $25 \%, 50 \%, 75 \%$ and $90 \%$ (T25\%, T50\%, T75\% and T90\%) of control twitch response. The maximum effect was determined as the maximum decrease of the twitch response. Time to reach a TOF ratio of 0.8 was calculated for all PMG and MMG signals simultaneously. Fast Fourier transformation was used to determine peak frequency of the first twitch response $30 \mathrm{sec}$ after start of stimulation.

Measurements from the three PMG monitoring sites and $\mathrm{MMG}$ were compared using repeated measures ANOVA followed by paired t tests with Bonferroni corrections. A $P$-value $<0.05$ was considered to be statistically significant. Sample size was determined based on a desired power of more than 0.90 , an estimated difference of $20 \%$ of mean onset time between phonomyographic and mechanomyographic measurements, and an anticipated onset time of four minutes. Continuous data were expressed as means and their standard deviations. Bias and precision were expressed as mean difference (MMG - PMG) and precision as standard deviation of this mean difference. The Bland-Altman test was used to determine mean difference and precision of the onset times, maximum effect, T25\%, T50\%, T75\%, T90\%, and TOF 0.8 measured using MMG and PMG at all monitoring. ${ }^{5}$

\section{Results}

We were able to obtain pharmacodynamic data with MMG and PMG in all 12 patients, who consisted of four men and eight women with a mean age of $52.1 \pm$ $18.7 \mathrm{yr}$, mean weight of $72.1 \pm 17.6 \mathrm{~kg}$ and mean height of $163.6 \pm 13.6 \mathrm{~cm}$. Hand temperature was higher than $34.0^{\circ} \mathrm{C}$ in all patients. Typical MMG and PMG signals are shown in Figure 3.

Phonomyographic measurements at the adductor pollicis and first dorsal interosseous muscles of onset time, maximum effect, T25\%, T50\%, T75\%, and T90\% 


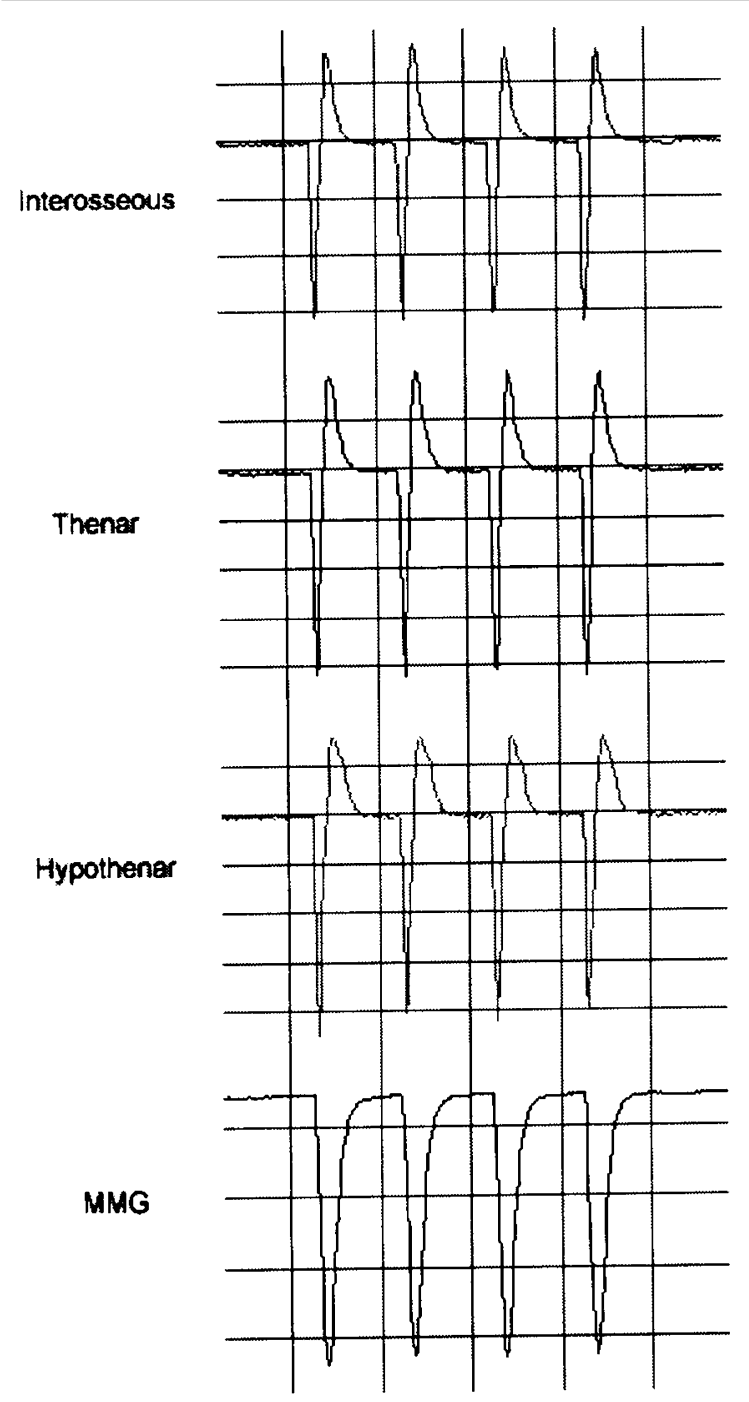

FIGURE 3 Typical signals for phonomyography and mechanomyography

Twitch height is measured peak-to-peak for phonomyographic signals, peak to baseline for mechanomyographic signals. First dorsal interosseus, thenar, hypothenar region measured using phonomyography, $\mathrm{MMG}=$ mechanomyography of the adductor pollicis muscle .

were not statistically different from mechanomyographic measurements at the adductor pollicis muscle (Table). However, phonomyographic measurements at the hypothenar muscles of $\mathrm{T} 50 \%, \mathrm{~T} 75 \%$, and $\mathrm{T} 90 \%$ were significantly shorter than mechanomyographic measurements at the adductor pollicis muscle and phonomyographic measurements at the first dorsal interosseus muscle. There was no significant difference in respect of onset, maximum effect, and offset of

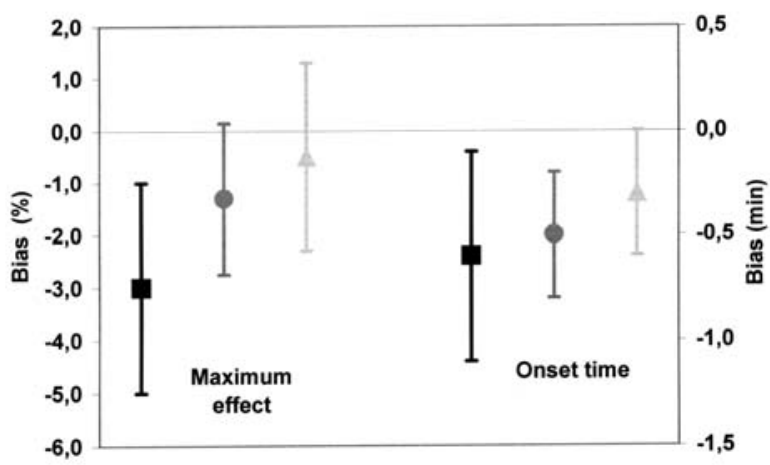

FIGURE 4 Graphic representation of bias and precision for maximum effect and onset time

Mean difference (bias, mechanomyography - phonomyography) \pm standard deviation (precision) between mechanomyography at adductor pollicis and phonomyography at first dorsal interosseus (full squares), thenar muscles (full circles) and hypothenar muscles (full triangles). Maximum effect $=$ maximum decrease of control twitch height; onset time $=$ time to reach maximum effect.

NMB between the adductor pollicis and first dorsal interosseus muscle. The peak frequencies for adductor pollicis muscle, first dorsal interosseus muscle and hypothenar muscles were $3.94 \pm 0.55 \mathrm{~Hz}, 4.18 \pm 0.65$ $\mathrm{Hz}$ and $4.14 \pm 0.47 \mathrm{~Hz}$ respectively without showing any significant difference. For mechanomyographic measurements of NMB at adductor pollicis muscle, best agreement and minimal bias was found with phonomyographic measurements at first dorsal interosseus and thenar muscles (Figures 4 and 5).

\section{Discussion}

PMG of the adductor pollicis muscle can replace MMG of the adductor pollicis muscle for monitoring $\mathrm{NMB}$ as demonstrated by minimal bias and good agreement. PMG of the first dorsal interosseus muscle can also be used to replace MMG of the adductor pollicis muscle for clinical purposes. Whereas onset, maximum effect, and recovery to TOF 0.8 at the hypothenar muscles, measured using PMG, were not significantly different from mechanomyographic results at the adductor pollicis muscle, significantly different values for $\mathrm{T} 50 \%$, T75\%, and T90\% preclude its use as a substitute for mechanomyographic measurements. In comparison to MMG, PMG has the advantage of easier setup and applicability at all muscles of interest including the larynx, diaphragm, corrugator supercilii muscle, and the hand muscles. Also, PMG is characterized by good signal stability. 


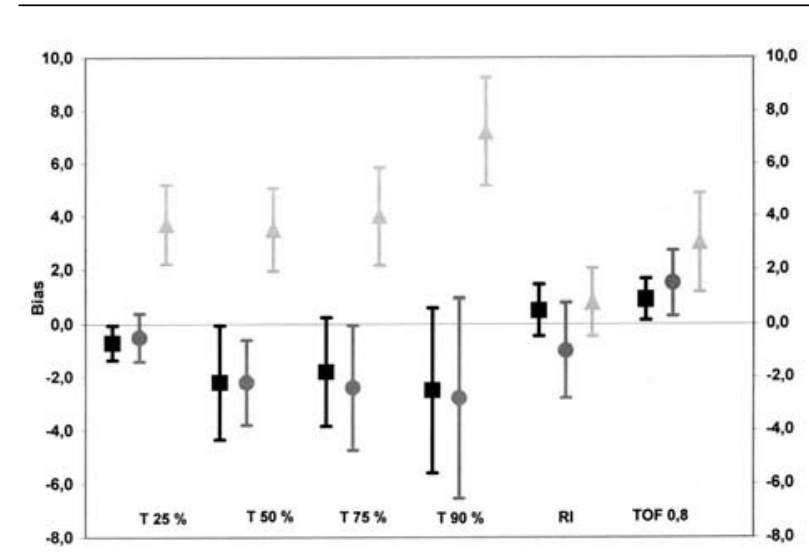

FIGURE 5 Graphic representation of bias and precision for time recovery curve

Mean difference (bias, mechanomyography - phonomyography ) \pm standard deviation (precision) between mechanomyography at adductor pollicis and phonomyography at first dorsal interosseus (full squares), thenar muscles (full circles) and hypothenar muscles (full triangles). T25\%, T75\%, T90\% = time to reach $25 \%, 75 \%$, $90 \%$ of control twitch height; RI = recovery index; time to $75 \%$ of control twitch height minus time to $25 \%$ of control twitch height $(\mathrm{T} 75 \%-\mathrm{T} 25 \%)$; TOF $0.8=$ time to reach a train-of-four ratio of 0.8 .

Anatomically, the first dorsal interosseus, hypothenar, and thenar muscles provide distinct sites for neuromuscular monitoring. The first dorsal interosseus muscle abducts the index finger and is situated within the dorsal groove between the first and second metacarpal bone. The belly of the first dorsal interosseus muscle is considered a deep belly, but its location is just below the skin. ${ }^{6}$ The only other muscle located in this area is the first lumbrical muscle, which inserts into the lateral band of the dorsal aponeurosis and causes extension of the interphalangeal joints. The first dorsal interosseus muscle is innervated by the ulnar nerve whereas the lumbrical muscle is innervated by the median nerve. Stimulation of the ulnar nerve without concomitant stimulation of the median nerve should avoid contraction of the latter muscle. Therefore, our microphone, placed at the groove between the first and second metacarpal bone, should have recorded the sole contraction of the first dorsal interosseus muscle. In contrast, microphones placed over the thenar and hypothenar region record sounds created by the contraction of several muscles. The three hypothenar muscles are the abductor digiti minimi, flexor digiti minimi, and opponens digit minimi muscle, which are all innervated by the deep motor branch of the ulnar nerve; thus, a microphone placed over the hypothenar area will record sounds created by the contraction of all three muscles. The thenar area consists of the abductor pollicis brevis, the flexor pollicis brevis, the opponens pollicis and the adductor pollicis muscle. Only the adductor pollicis muscle and the medial head of the two-headed flexor pollicis brevis muscle are innervated by the ulnar nerve. A microphone placed over the thenar region will record signals emitted by contraction of these two muscles. Since the flexor pollicis brevis muscle flexes and adducts the proximal phalanx of the thumb, even MMG of the thumb will measure contraction not only of the adductor pollicis muscle, but also of the flexor pollicis brevis.

$\mathrm{NMB}$ at the different hand muscles is not uniform and could be explained by dimension of muscular fibres, ${ }^{7}$ blood perfusion ${ }^{8,9}$ and density of acetylcholine receptors. One previous study found no significant difference in type I and type II fibre size between the adductor pollicis and the first dorsal interosseus muscle. ${ }^{10}$ This observation could explain in part the similar pharmacodynamic behaviour found in our study for both muscles. So far there are no studies on the fibre size of any of the hypothenar muscles. Although the blood supply is anatomically different for hypothenar, thenar, and first dorsal interosseus muscles, the similar onset times do not suggest significantly different blood supplies as reason for the pharmacodynamic differences of the hand muscles.

Detailed monitoring of differential NMB at intrinsic hand muscles has been performed mainly using electromyography. ${ }^{4,11-13}$ Whereas some studies have found practically interchangeable results for all intrinsic hand muscles, some work has indicated that the hypothenar muscles are more resistant to neuromuscular blocking agents than the thenar muscles. ${ }^{14}$ Furthermore, electromyography has been shown to differ significantly from mechanomyographical results ${ }^{13,15,16}$ and is rarely used for research purposes or in clinical routine. PMG offers the advantage of easy setup, applicability in research and clinical routine, and differentiation between different hand muscles. Our study did not find significant differences between PMG measurements at the thenar area or first dorsal interosseus muscle and the adductor pollicis measured using MMG. Due to the large inter-patient variability of the measured times, a larger sample size (more than 150 patients) would be needed to demonstrate a statistically significant difference between phonomyographic measurements and mechanomyographic measurements at the first dorsal interosseus or thenar muscles. However, this does not change the good agreement and low bias between the two methods at the thenar region or the first dorsal interosseus muscle. 
Our study shows that PMG of the first dorsal interosseus muscle and of the thenar area shows better agreement with MMG of the thumb than PMG of the hypothenar area. The different onset and recovery times of $\mathrm{NMB}$ at the three monitoring sites might be explained by structural and physiological differences between the muscles.

\section{References}

1 Hemmerling TM, Babin D, Donati F.

Phonomyography as a novel method to determine neuromuscular blockade at the laryngeal adductor muscles: comparison with the cuff pressure method. Anesthesiology 2003; 98: 359-63.

2 Hemmerling TM, Donati F, Beaulieu P, Babin D. Phonomyography of the corrugator supercilii muscle: signal characteristics, best recording site and comparison with acceleromyography. Br J Anaesth 2002; 88: 389-93.

3 Paloheimo MP, Wilson RC, Edmonds HL Jr, Lucas LF, Triantafillou AN. Comparison of neuromuscular blockade in upper facial and hypothenar muscles. J Clin Monit 1988; 4: 256-60.

4 Harper NJ. Comparison of the adductor pollicis and the first dorsal interosseous muscles during atracurium and vecuronium blockade: an electromyographic study. Br J Anaesth 1988; 61: 477-8.

5 Bland JM, Altman DG. Statistical methods for assessing agreement between two methods of clinical measurement. Lancet 1986; 1: 307-10.

6 Gray $H$. Anatomy of the Human Body. Philadelphia: Lea \& Febiger, 1918; Bartleby.com, 2000.

7 Ibebunjo, C, Hall LW. Muscle fibre diameter and sensitivity to neuromuscular blocking drugs. Br J Anaesth 1993; 71: 732-3.

8 Heneghan CP, Findley IL, Gillbe CE, Feldman SA. Muscle blood flow and rate of recovery from pancuronium neuromuscular blockade in dogs. Br J Anaesth 1978; 50: 1105-8.

9 Goat VA, Yeung ML, Blakeney C, Feldman SA. The effect of blood flow upon the activity of gallamine triethiodide. Br J Anaesth 1976; 48: 69-73.

10 Polgar J, Johnson MA, Weightman D, Appleton D. Data on fibre size in thirty-six human muscles. An autopsy study. J Neurol Sci 1973; 19: 307-18.

11 Engbaek J, Roed J, Hangaard N, Viby-Mogensen J. The agreement between adductor pollicis mechanomyogram and first dorsal interosseous electromyogram. A pharmacodynamic study of rocuronium and vecuronium. Acta Anaesthesiol Scand 1994; 38: 869-78.

12 Kopman AF. The dose-effect relationship of metocurine: the integrated electromyogram of the first dorsal interosseous muscle and the mechanomyogram of the adductor pollicis compared. Anesthesiology 1988; 68: 604-7.

13 Engbaek J, Roed J. Differential effect of pancuronium at the adductor pollicis, the first dorsal interosseous and the hypothenar muscles. An electromyographic and mechanomyographic dose-response study. Acta Anaesthesiol Scand 1992; 36: 664-9.

$14 \mathrm{Katz} R L$. Electromyographic and mechanical effects of suxamethonium and tubocurarine on twitch, tetanic and post-tetanic responses. $\mathrm{Br} \mathrm{J}$ Anaesth 1973; 45: 849-59.

15 Kopman AF. The relationship of evoked electromyographic and mechanical responses following atracurium in humans. Anesthesiology 1985; 63: 208-11.

16 Hofmockel VR, Benad G, Pobl B, Brabmstedt R. Measuring muscle relaxation with mivacurium in comparison with mechano- and electromyography (German). Anaesthesiol Reanim 1998; 23: 72-80. 